\title{
IMPLEMENTASI ALGORITMA NAZIEF- ADRIANI PADA FITUR TEBAK KATA DI WEB EDUKASI BAHASA INDONESIA
}

\author{
Handrie Noprisson ${ }^{1}$, Vina Ayumi ${ }^{2}$ \\ Fakultas IImu Komputer, Universitas Mercu Buana \\ Jl. Raya Meruya Selatan, Kembangan, Jakarta 11650 \\ E-mail: 1handrie.noprisson@mercubuana.ac.id, 2 vina.ayumi@mercubuana.ac.id
}

\begin{abstract}
One of the rules or grammar of Bahasa Indonesia that must be known is about the introduction of basic words. In the field of computing, one of the algorithms developed and related to the word aspect in Indonesian is the Nazief-Adriani algorithm. The research methodology consists of 5 stages: data collection, analysis, design, implementation and report writing. Implementation of the Nazief-Adriani algorithm is performed on a guessword game feature that is used to guess the underlying word of the existing affix. As a result of the research, the Nazief-Adriani algorithm has been successfully implemented and tested for several words of attribute (pelatihan, pendidikan dan menghasilkan) on the basic word-guess games on the Web Indonesian Education well but the lack of the Nazief-Adriani algorithm is incapable of detecting and removing affix-infix or middle affix / inserts.
\end{abstract}

Abstrak - Salah satu aturan atau tata bahasa Bahasa Indonesia yang harus diketahui adalah mengenai pengenalan kata dasar dan kata berimbuhan. Dalam bidang komputasi, salah satu algoritma yang dikembangkan dan berhubungan dengan aspek kata dasar dan kata berimbuhan Bahasa Indonesia adalah algoritma Nazief-Adriani. Metodologi penelitian terdiri dari 5 tahap yaitu pengumpulan data, analisis, desain, implementasi dan penulisan laporan. Implementasi algoritma Nazief-Adriani dilakukan pada fitur permainan tebak kata yang digunakan untuk menebak kata dasar dari imbuhan yang ada. Sebagai hasil penelitian, algoritma Nazief-Adriani berhasil diimplementasikan dan diuji coba untuk beberapa kata imbuhan (pelatihan, pendidikan dan menghasilkan) pada permainan tebak kata dasar di Web Edukasi Bahasa Indonesia dengan baik namun kekurangan dari algoritma Nazief-Adriani adalah belum mampunya untuk mendeteksi dan menghapus afiks-infiks atau imbuhan tengah/sisipan.

Keywords- Pemrosesan Teks, Bahasa Indonesia, Nazief Adriani

\section{Pendahuluan}

Perkembangan teknologi informasi dan komunikasi telah menciptakan sejumlah variasi aplikasi yang dapat digunakan oleh masyarakat umum. Beberapa aplikasi dalam bentuk offline maupun online telah menjadi kebutuhan untuk menunjang aktifitas sehari-hari. Aplikasi saat ini yang cukup menarik untuk dikembangkan adalah aplikasi yang dapat digunakan sebagai media pembelajaran untuk menunjang peningkatan intelektual pengguna.

Salah satu jenis intelektual yang harus dimiliki dan dikembangkan adalah kemampuan intelektual berbahasa. Di Indonesia, bahasa resmi yang digunakan sebagai alat komunikasi adalah bahasa Indonesia. Meskipun Bahasa Indonesia sering digunakan dalam kehidupan sehari-hari, namun banyak masyarakat terutama pelajar yang kurang mengetahui dengan baik aturan dalam menggunakan Bahasa Indonesia baik dalam lisan maupun tulisan [1].

Seperti yang dilansir Kompas dalam pemberitaannya di media internet, hasil pengumuman ujian nasional (UN) yang serentak sudah dilakukan selama sepekan di sejumlah daerah, termasuk Kota Malang, Jawa Timur, nilai Bahasa Inggris sejumlah siswa lebih tinggi dibanding nilai Bahasa Indonesia [1]. Padahal sebagai generasi penerus bangsa terpelajar, seharusnya lebih mengenal dan mengetahui tata Bahasa 
Indonesia dibandingkan tata Bahasa Asing. Salah satu aturan atau tata bahasa Bahasa Indonesia yang harus diketahui adalah mengenai pengenalan kata dasar dan kata berimbuhan.

Dalam bidang komputasi, untuk pengenalan sebuah pola dikenal dengan pattern recognition [2], [3]. Salah satu algoritma yang dikembangkan dan berhubungan dengan pengenalan pola aspek kata dasar dan kata berimbuhan Bahasa Indonesia adalah algoritma Nazief-Adriani. Algoritma Nazief-Adriani sendiri merupakan algoritma stemming yang mentransformasikan kata-kata yang terdapat dalam suatu dokumen ke kata-kata akarnya (root word) dengan menggunakan aturan-aturan tertentu. Sebagai contoh, kata bersama, kebersamaan, menyamai, akan ditransformasi ke root word-nya yaitu "sama". Algoritma stemming untuk bahasa yang satu berbeda dengan algoritma stemming untuk bahasa lainnya, sebab algoritma stemming dibuat dengan menyesuaikan dengan struktur bahasa yang akan digunakan [4].

Berdasarkan latar belakang diatas dengan memanfaatkan Algoritma NaziefAdriani, ilmu pemrograman website serta ilmu sastra mengenai kata dasar dan berimbuhan, maka penulis tertarik untuk melakukan penelitian dan memilih judul "Implementasi Algoritma NaziefAdriani Untuk Fitur Tebak Kata di Web Edukasi Bahasa". Aplikasi lainnya juga telah dikembangkan untuk mempromosikan kembali warisan [3], [5] dan identitas bangsa Indonesia [6]. Diharapkan aplikasi berbasis website ini juga dapat digunakan sebagai media edukasi bagi masyarakat maupun pelajar untuk lebih mengenal Bahasa Indonesia sebagai identitas bangsa terutama mengenai kata-kata dasar dan kata berimbuhan.

\section{Studi Literatur}

\section{A. Penelitian Terkait}

Penelitian oleh [7] yang melakukan penelitian mengenai kemiripan teks menggunakan algoritma Nazief-Adriani untuk mengubah kata imbuhan menjadi kata dasar. Kemiripan teks dilihat dari hasil perhitungan cosine similarity index dari kata-kata dasar yang ada dalam teks tersebut.
Selain itu, penelitian oleh [8] melakukan penelitian mengenai pengklasifikasian dokumen teks. Penelitian menggabungkan beberapa algoritma antara lain Nazief Adriani, KNN dan Fungsi Similarity Cosin. Pada penelitian ini pengklasifikasian dokumen teks dilihat dari kata dasar yang dalam dokumen teks. Pengubahan kata imbuhan yang ada dalam dokumen teks menjadi kata dasar menggunakan algoritma Nazief Adriani.

\section{B. Algoritma Nazief Adriani}

Algoritma Nazief dan Mirna Adriani ini memiliki tahap-tahap sebagai berikut [4]:

1. Cari kata yang akan distem dalam kamus. Jika ditemukan maka diasumsikan bahwa kata tesebut adalah root word. Maka algoritma berhenti.

2. Inflection Suffixes ("-lah", “-kah", “ku", "-mu", atau "-nya") dibuang. Jika berupa particles ("-lah", "-kah", "-tah" atau "-pun") maka langkah ini diulangi lagi untuk menghapus Possesive Pronouns ("-ku", "-mu", atau "-nya"), jika ada.

3. Hapus Derivation Suffixes ("-i", “-an" atau "-kan"). Jika kata ditemukan di kamus, maka algoritma berhenti. Jika tidak maka ke langkah 3a.

a. Jika "-an" telah dihapus dan huruf terakhir dari kata tersebut adalah "-k", maka "-k" juga ikut dihapus. jika kata tersebut ditemukan dalam kamus maka algoritma berhenti. jika tidak ditemukan maka lakukan langkah 3b.

b. Akhiran yang dihapus ("-i", "-an" atau "-kan") dikembalikan, lanjut ke langkah 4.

4. Hapus Derivation Prefix. Jika pada langkah 3 ada sufiks yang dihapus maka pergi ke langkah $4 a$, jika tidak pergi ke langkah 4b.

a. Periksa tabel kombinasi awalanakhiran yang tidak diijinkan. Jika ditemukan maka algoritma berhenti, jika tidak pergi ke langkah 4b.

b. For $\mathrm{i}=1$ to 3 , tentukan tipe awalan kemudian hapus awalan. Jika root word belum juga ditemukan lakukan langkah 5, jika sudah 
maka algoritma berhenti. Catatan: jika awalan kedua sama dengan awalan pertama algoritma berhenti.

\section{Melakukan Recoding.}

6. Jika semua langkah telah selesai tetapi tidak juga berhasil maka kata awal diasumsikan sebagai root word. Proses selesai.

Tipe awalan ditentukan melalui langkahlangkah berikut:

1. Jika awalannya adalah: "di-", "ke-", atau "se-" maka tipe awalannya secara berturut-turut adalah "di-", "ke-", atau "se-".

2. Jika awalannya adalah "te-", "me-", "be-", atau "pe-" maka dibutuhkan sebuah proses tambahan untuk menentukan tipe awalannya.

3. Jika dua karakter pertama bukan "di-", “ke-", "se-", “te-", “be-", "me-", atau "pe-" maka berhenti.

TABEL I

KOMBINASI AWALAN AKHIRAN YANG TIDAK DIIJINKAN

\begin{tabular}{|l|l|}
\hline $\begin{array}{c}\text { Awal } \\
\text { an }\end{array}$ & \multicolumn{1}{c|}{$\begin{array}{c}\text { Akhiran yang tidak } \\
\text { diijinkan }\end{array}$} \\
\hline be- & $-\mathrm{i}$ \\
\hline di- & $-a n$ \\
\hline ke- & $-1,-$ kan \\
\hline me- & - an \\
\hline se- & - I, kan \\
\hline
\end{tabular}

Sumber: [4]
1. Aturan untuk reduplikasi.

a. Jika kedua kata yang dihubungkan oleh kata penghubung adalah kata yang sama maka root word adalah bentuk tunggalnya, sebagai contoh: "buku-buku" root word-nya adalah "buku".

b. Kata lain, misalnya "bolak-balik", "berbalas-balasan, dan "seolaholah". Untuk mendapatkan root word-nya, kedua kata diartikan secara terpisah. Jika keduanya memiliki root word yang sama maka diubah menjadi bentuk tunggal, contoh: kata "berbalasbalasan", "berbalas" dan "balasan" memiliki root word yang sama yaitu "balas", maka root word "berbalas-balasan" adalah "balas". Sebaliknya, pada kata "bolak-balik", "bolak" dan "balik" memiliki root word yang berbeda, maka root word-nya adalah "bolak-balik".

2. Tambahan bentuk awalan dan akhiran serta aturannya.

a. Untuk tipe awalan "mem-", kata yang diawali dengan awalan "memp-" memiliki tipe awalan "mem-".

b. Tipe awalan "meng-", kata yang diawali dengan awalan "mengk-" memiliki tipe awalan "meng-".

\section{Metodologi Penelitian}

Metodologi penelitian terdiri dari 5 tahap yaitu pengumpulan data, analisis, desain, implementasi dan penulisan laporan seperti yang terlihat di Gambar 1.

TABEL ॥

JENIS AWALAN BERDASARKAN TIPE AWALANNYA

\begin{tabular}{|l|l|}
\hline $\begin{array}{l}\text { Tipe } \\
\text { Awalan }\end{array}$ & $\begin{array}{l}\text { Akhiran yang harus } \\
\text { dihapus }\end{array}$ \\
\hline di- & di- \\
\hline Ke- & Ke- \\
\hline Se- & Se- \\
\hline Te- & Te- \\
\hline Ter- & Ter- \\
\hline Ter-luluh & Ter- \\
\hline
\end{tabular}

Sumber: [4]

Untuk mengatasi keterbatasan pada algoritma di atas, maka ditambahkan aturan-aturan dibawah ini: 


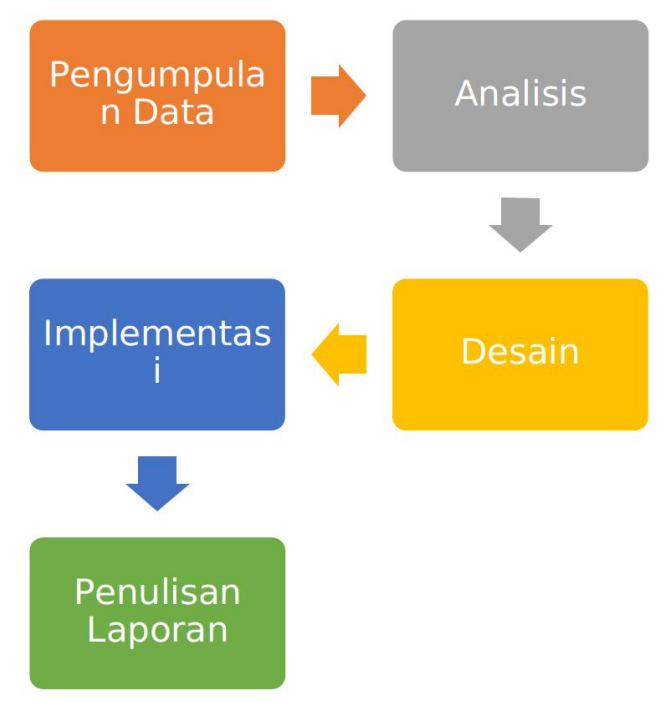

Gbr. 1 Metodologi Penelitian

Tahap pengumpulan data dilakukan dengan cara studi pustaka dan mengumpul dataset teks bahasa Indonesia. Tahap analisis dilakukan dengan dilakukan dengan mempelajari cara kerja algoritma terhadap dataset yang sudah dikumpulkan. Tahap desain dilakukan dengan cara merancang aplikasi sesuai dengan hasil analisis. Tahap implementasi dilakukan dengan cara menerjemahkan desain menjadi kode pemrograman PHP. Hasil implementasi dan analisis kinerja algoritma pada aplikasi kemudian dituliskan dalam bentuk laporan penelitian.

\section{Hasil dan Diskusi}

Penelitian ini fokus pengimplementasian algoritma NaziefAdriani pada salah satu fitur Web Edukasi Bahasa, sehingga web edukasi hanya digambarkan dalam bentuk use case diagram dan antar muka web edukasi.

\section{A. Use Case Diagram}

Pada Web Edukasi Bahasa terdiri dari fungsional antara laian, agenda, berita, dokumen, permainan tebak kata dan sign-in, seperti yang terlihat pada Gambar 2 berikut ini.

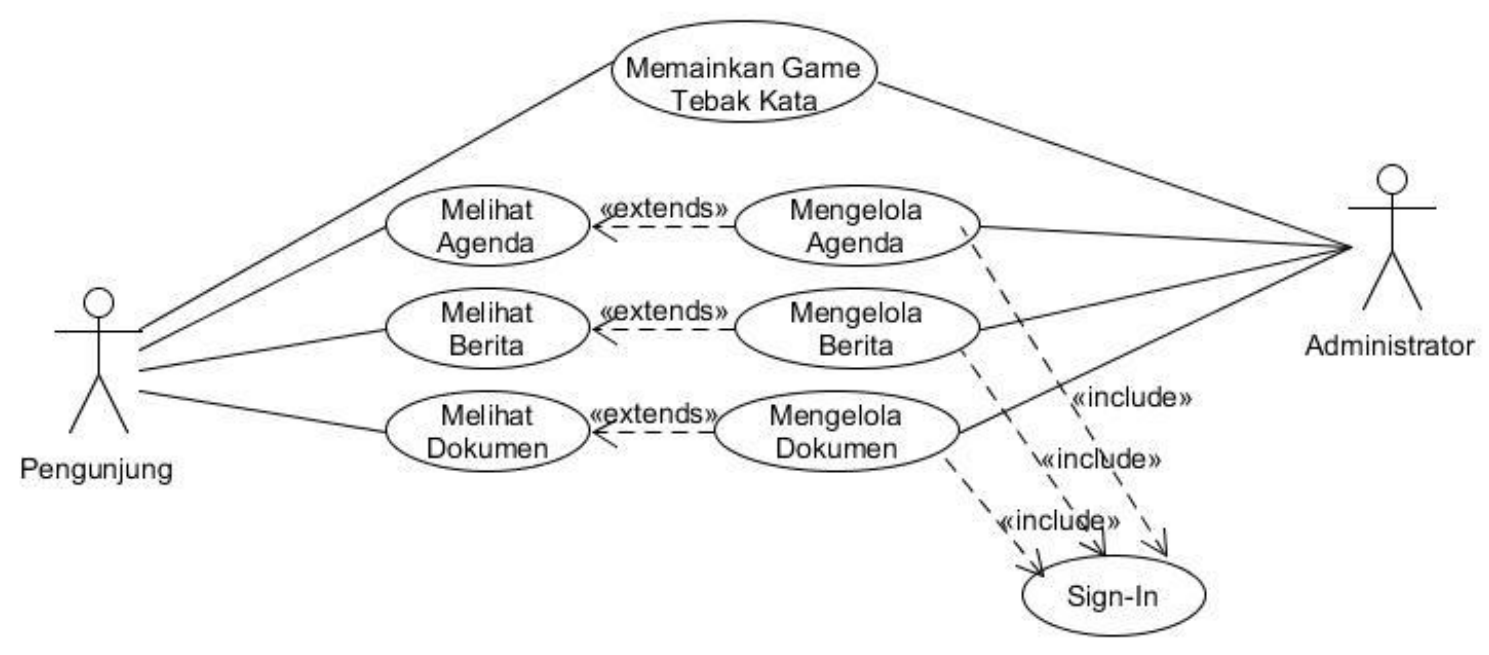

Gbr. 2 Use Case Diagram Web Edukasi

\section{B. Antar Muka}

Pada penelitian ini telah berhasil membangun Web Edukasi Bahasa dengan antar muka yang sederhana yang dibagi menjadi tiga section yaitu, header, body dan footer seperti yang ditampilkan pada Gambar 3 berikut ini. 


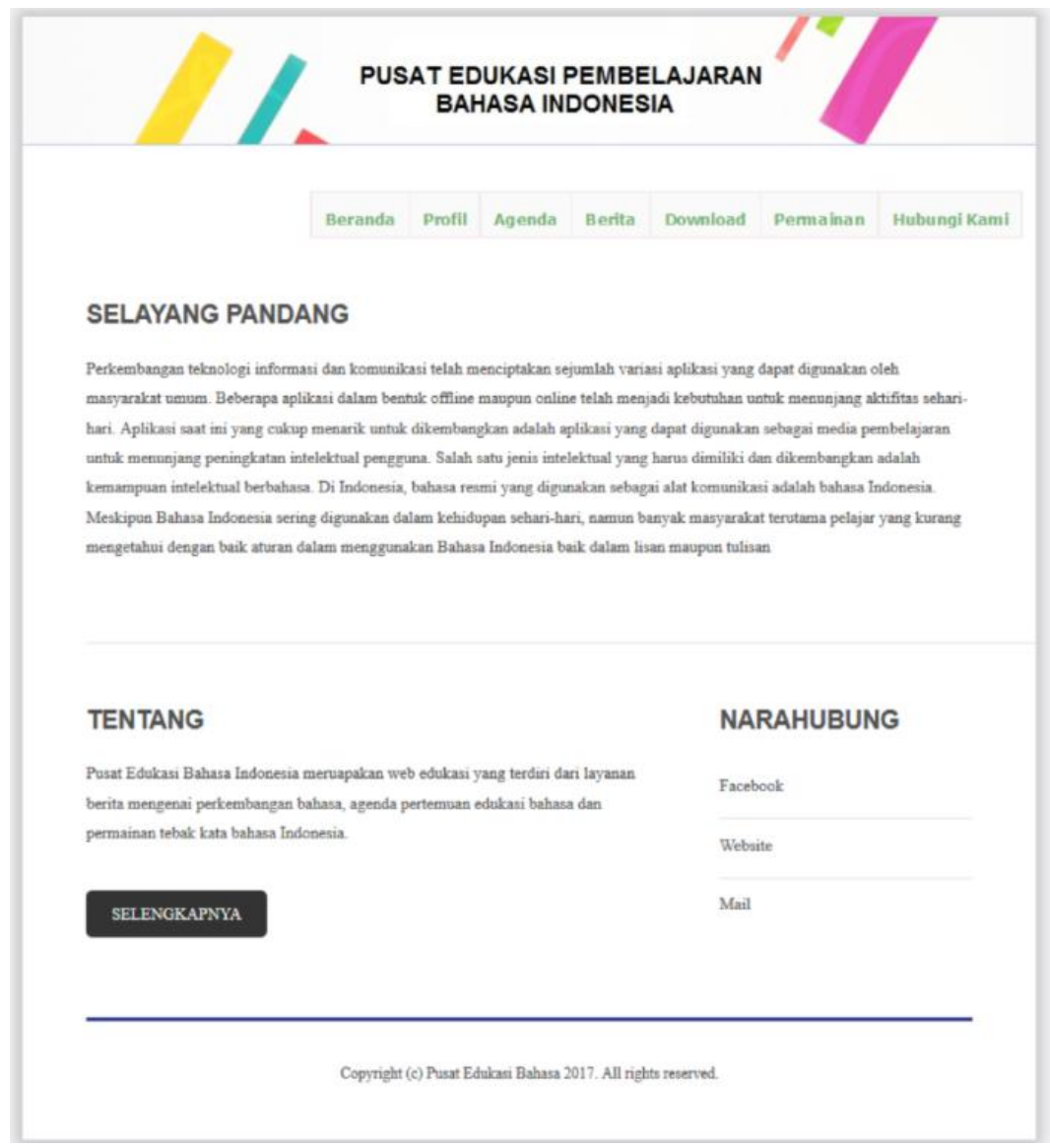

Gbr. 3 Antar Muka Web Edukasi

Implementasi algoritma Nazief-Adriani dilakukan pada fitur permaian tebak kata yang digunakan untuk menebak kata dasar dari imbuhan yang ada. Algoritma Nazief-Adriani ini sering digunakan untuk proses stemming atau proses pengubahan berimbuhan menjadi kata dasar dengan mengelompokkan bentuk imbuhan menjadi Inflection Suffixes ("-lah", "-kah", "-ku", "-mu", atau "-nya"), Derivation Suffixes ("-i", “an" atau "-kan"), dan Derivation Prefix. Namun, keakuratan dari algoritma ini tergantung pada banyaknya kata dasar yang ada dalam database. Potongan source code pemrograman dari proses stemming dapat dilihat pada Gambar 4.

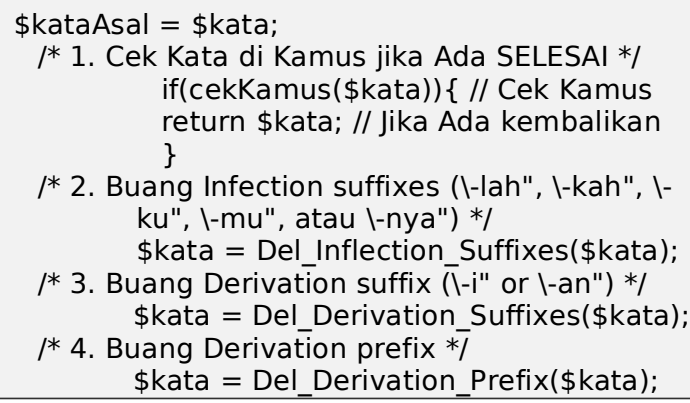

/*2. Buang Infection suffixes (I-lah", I-kah", Iku", ।-mu", atau \-nya") *I \$kata = Del Inflection Suffixes(\$kata);

/*3. Buang Derivation suffix (\-i" or $\backslash$-an") *I \$kata = Del_Derivation_Suffixes(\$kata);

/*4. Buang Derivation prefix */ $\$$ kata = Del_Derivation_Prefix (\$kata);

return \$kata;

function Del_Inflection_Suffixes(\$kata) \{ \$kataAsal = \$käta;

if(eregi('([km]u|nya|[kl]ah|pun)\$',\$kata)

) $\{$ // Cek Inflection Suffixes

$\$ \mathrm{kata}=$

eregi_replace('([km]u|nya|[kI]ah|pun)\$',",\$kata );

if(eregi('([klt]ah|pun)\$',\$kata)) \{ // Jika berupa particles ("-lah", “-kah", "-tah" atau “-pun”)

if(eregi('([km]u|nya)\$',\$_kata))\{

// Hapus Possesive Pronouns ("-ku", "-mu", atau "-nya")

\$_kata_ =

eregi_replace('([km]u|nya)\$',",\$_kata);

$$
\begin{gathered}
\text { return \$_kata_; } \\
\text { \}return \$_kata; }
\end{gathered}
$$$$
\text { \} }
$$

return \$kataAsal;

\}..

function Del Derivation Suffixes(\$kata) \{ $\$$ kataAsal = \$kata;

Suffixes if(preg_match('/(kan)\$/',\$kata)) \{ // Cek

preg_replace('/(kan)\$/',",\$kata); if(cekKamus(\$_kata)) \{ // Cek Kamus

$$
\text { return \$_kata; }
$$




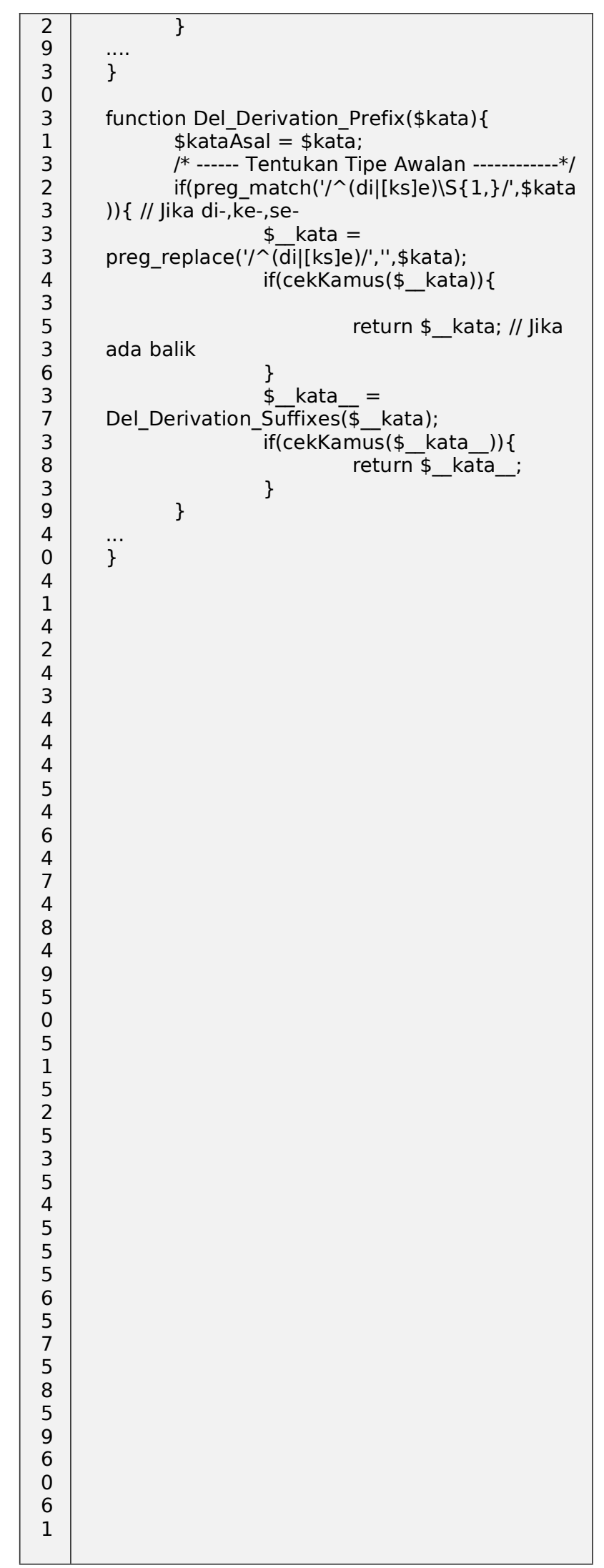

Gbr. 4 Source Code Proses Stemming

Bahasa Indonesia cukup rumit dalam hal tata penulisan dengan adanya banyak aturan dalam penulisan imbuhan meliputi afiks-prefiks (imbuhan awal/awalan), afiks infiks (imbuhan tengah/sisipan), afiks-sufiks (imbuhan akhir/akhiran), konfiks imbuhan awal dan akhir yang sama-sama membentuk satu arti dan afiks gabung (imbuhan awal dan akhir, dan tiap-tiap imbuhan masih tetap). Kekurangan dari algoritma Nazief-Adriani adalah belum mampunya untuk mendeteksi dan menghapus afiksinfiks atau imbuhan tengah/sisipan. Misalnya pada kata "pemetaan" akan ditransformasi menjadi "meta" dikarenakan imbuhan pada kata tersebut dikenali sebagai imbuhan "pe-an", sehingga untuk mengatasinya tabel baru yang berisi imbuhan afiks-infiks dan kata dasarnya yang kemudian diproses dengan menggunakan kode array_intersect, array_diff dan implode. Pada Web Edukasi Bahasa, pengguna dapat memilih menu "permainan" sepert yang terlihat pada Gambar 5.

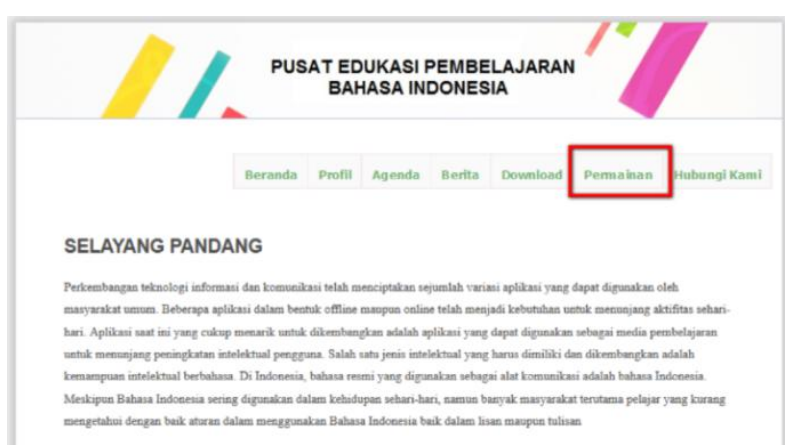

Gbr. 5 Pemilihan Menu Permainan

Kemudian dilakukan permainan untuk tebak kata dasar untuk kata "pendidikan", kemudian dilakukan proses stemming dan dicocokan dengan jawaban yang dimasukkan oleh pengguna, sebagai contoh pengguna memasukkan kata "didik" seperti yang terlihat pada Gambar 6.

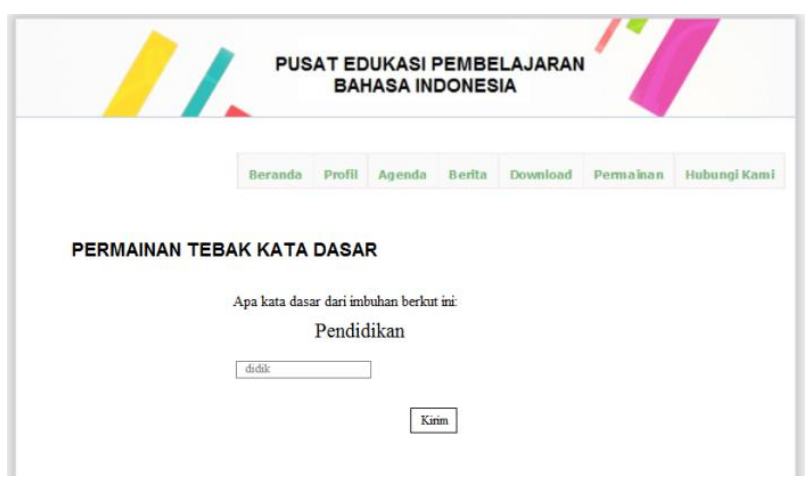

Gbr. 6 Antar Muka Tebak Kata 'Pendidikan' 
Berdasarkan jawaban pengguna dan hasil proses stemming, kata pendidikan memiliki kata dasar 'didik', sehingga antar muka akan menampilkan informasi 'Jawaban Anda Benar' seperti yang terlihat pada Gambar 7.

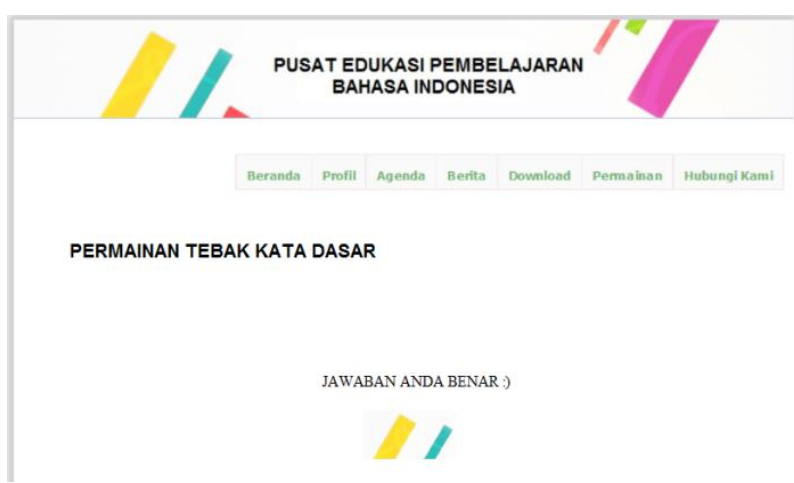

Gbr. 7 Antar Muka 'Jawaban Benar'

\section{Kesimpulan}

Kesimpulan yang dapat diambil dari penelitian ini adalah sebagai berikut:

1. Penelitian ini menghasilkan Web Edukasi Bahasa Indonesia yang telah dilengkapi permainan tebak kata dasar yang dibangun dengan menggunakan bahasa pemograman Hypertext Markup Language (HTML), Hypertext Preprosessor (PHP), Cascading Style Sheet (CSS), Javascript dan Structured Query Language (SQL) dengan berbantuan editor Notepad++ serta MySQL sebagai database server.

2. Algoritma Nazief-Adriani berhasil diimplementasikan dan diuji coba untuk beberapa kata imbuhan (pelatihan, pendidikan dan menghasilkan) pada permainan tebak kata dasar di Web Edukasi Bahasa Indonesia dengan baik.

\section{Referensi}

[1] J. Yudono, "Bahasa Indonesia Kian Kurang Diminati," Kompas.com, 2011. [Online]. Available: https://edukasi.kompas.com/read/20 11/05/21/18042068/Bahasa.Indonesi a.Kian.Kurang.Diminati. [Accessed: 24-Mar-2018].

[2] I. Nurhaida, R. Manurung, and A. M.
Arymurthy, "Extraction Methods for Batik Recognition," in 2012 International Conference on Advanced Computer Science and Information Systems (ICACSIS), 2012, pp. 978-979.

[3] I. Nurhaida, A. Noviyanto, $M$. Manurung, and A. M. Arymurthi, “Automatic Indonesian's Batik Pattern Recognition using SIFT Approach," in ICCSCl - 1st International Conference on Computer Science and Computational Intelligence, Jakarta, 2015.

[4] L. Agusta, “Perbandingan Algoritma Stemming Porter Dengan Algoritma Nazief \& Adriani Untuk Stemming Dokumen Teks Bahasa Indonesia," in Konferensi Nasional Sistem dan Informatika, 2009, pp. 196-201.

[5] I. Nurhaida, R. Manurung, and A. M. Arymurthy, comparison analysis features extraction methods for batik recognition," in International Conference on Advanced Computer Science and Information Systems (ICACSIS), 2012.

[6] D. Fitrianah, A. N. Hidayanto, R. A. Zen, and A. M. Arymurthy, "APDATI: E-Fishing Logbook for Integrated Tuna Fishing Data Management," J. Theor. Appl. Inf. Technol., vol. 75, no. 2, 2015.

[7] R. V. Imbar, Adelia, Mewati Ayub, and A. Rehatta, "Implementasi Cosine Similarity dan Algoritma Smith-Waterman untuk Mendeteksi Kemiripan Teks," J. Inform., vol. 10, no. 1, 2014.

[8] D. Susandi and U. Sholahudin, "Pemanfaatan Vector Space Model pada Penerapan Algoritma Nazief Adriani, KNN dan Fungsi Similarity Cosine untuk Pembobotan IDF dan WIDF pada Prototipe Sistem Klasifikasi Teks Bahasa Indonesia," J. ProTekInfo, vol. 3, no. 1, 2016. 